\title{
CT-RITMO Study: rate of infarction growth in acute stroke CT perfusion
}

\section{sequential studies}

Trillo S. ${ }^{1}$; de Albóniga-Chindurza A. ${ }^{2}$; Aguirre C. ${ }^{1}$; Bárcena E. ${ }^{3}$; Lourido D. ${ }^{4}$; Ramos C. ${ }^{1}$; Martínez Vicente

$\mathrm{L}^{1}$; de Felipe A. ${ }^{2}$; Alcántara P${ }^{1}$; Ximénez-Carrillo Á. ${ }^{1}$; Caniego J.L. ${ }^{3}$; Masjuán J. ${ }^{2}$; Vivancos J. ${ }^{1}$

1 Stroke Unit, Neurology Department. 3 Radiology Department. Hospital Universitario La Princesa. Madrid, Spain.

2 Stroke Unit, Neurology Department. 4 Radiology Department. Hospital Universitario Ramón y Cajal. Madrid, Spain.

\section{BACKGROUND}

- Cerebral infarction core can be assessed using CT-Perfusion cerebral blood volume maps(CBV-core). However, no study has evaluated the CBV-core changes during stroke progression yet.

- The CT-RITMO (CT-Perfusion Rate of Infarction growTh in MCA ThrOmbectomy) study goal is to evaluate factors related to infarction growth in hyperacute stroke.

\section{METHODS}

- We conducted a retrospective study of consecutive patients with MCA territory acute stroke transferred between 2 stroke centers and undergoing endovascular treatment. CBV-core was estimated in sequential CT-Perfusion(CTP) studies (first CTP performed in the shipping center and a second one in the treatment center).

- Clinical and radiological variables were correlated with infarction growth.

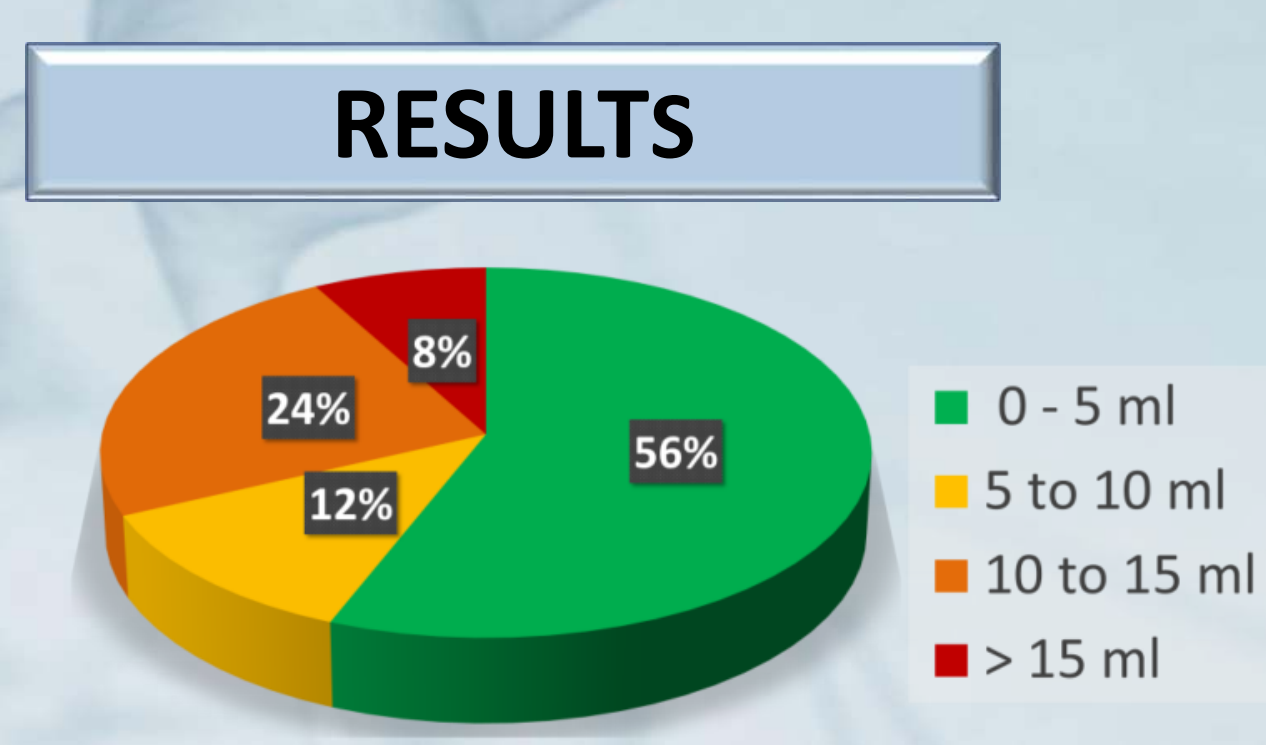

67 patients transferred

58 TCP repeated

CBV-core growth
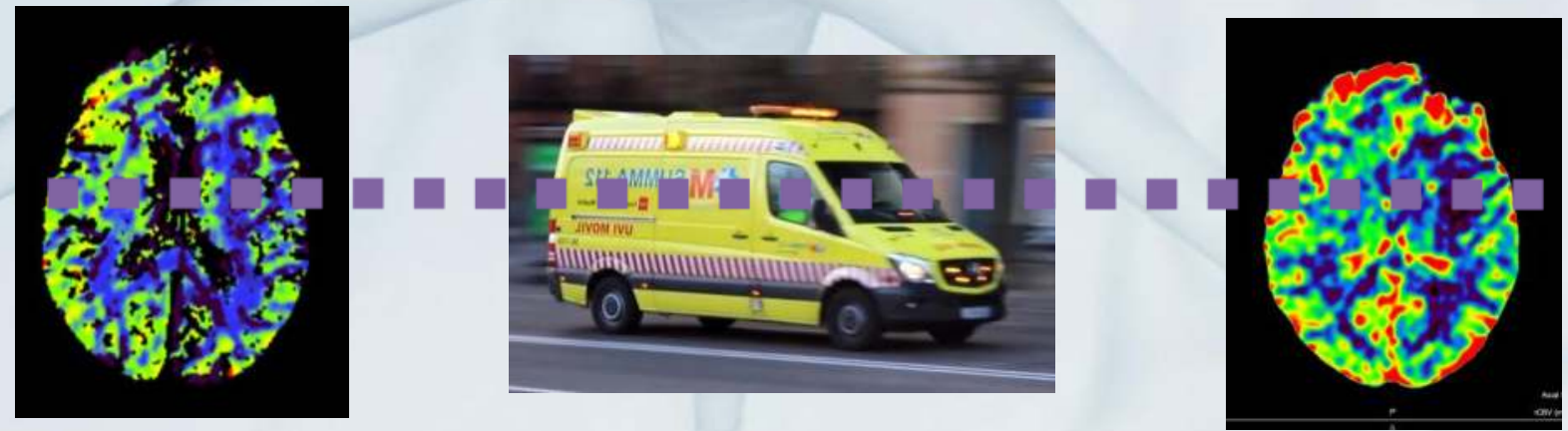

50 patients with 2 TCP studies available

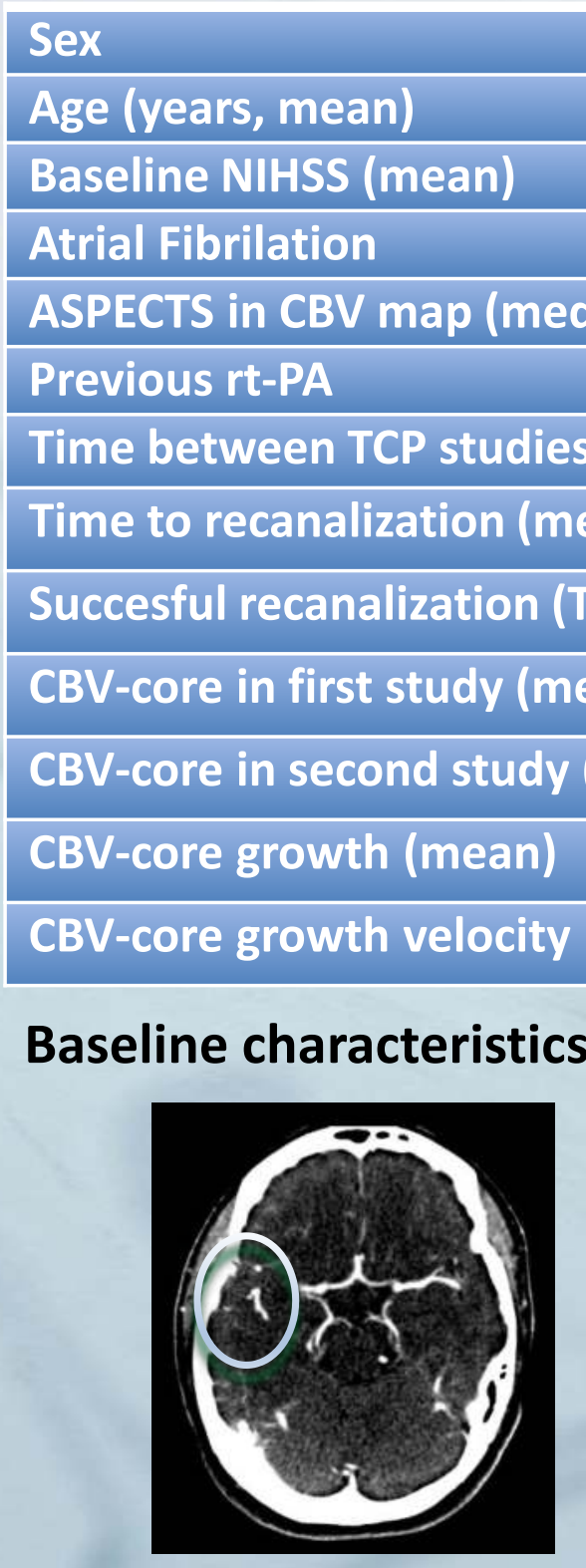

\section{CONCLUSIONS}

- Our study suggests that CBV-core growth tends to be low but with a significant variability.

- Infarction growth was associated with factors already known as relevant in stroke, but our study points out their importance even for a short period of time in the hyperacute phase.
Collateral circulation (Christoforidis scale in CTASI)
Factors related to higher CBV-core growth
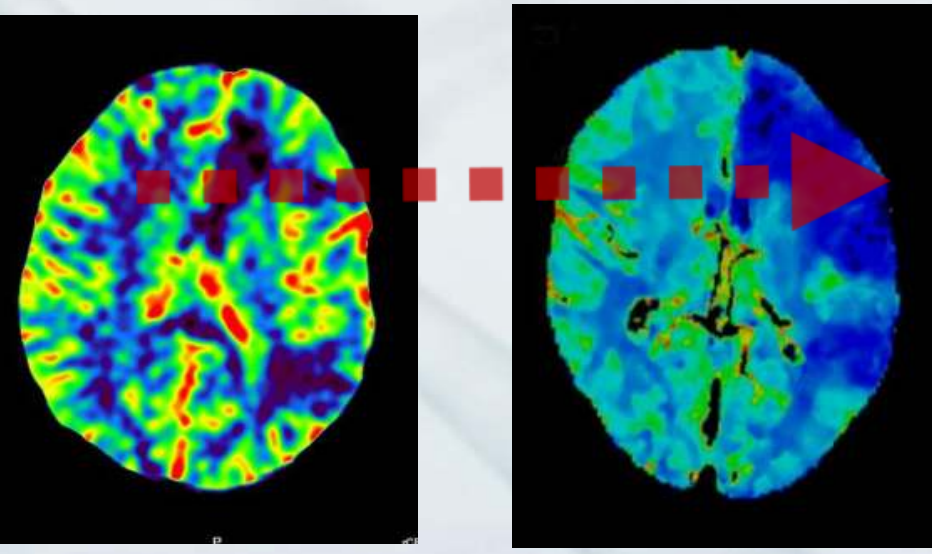

- Higher glycaemia, Rho=0,33; $p=0,03$

- Higher creatinine levels, Rho=0,3; $p=0,05$ )

- Higher baseline NIHSS Rho=0,28; $p=0,05$.

Factors related to lower CBV-core
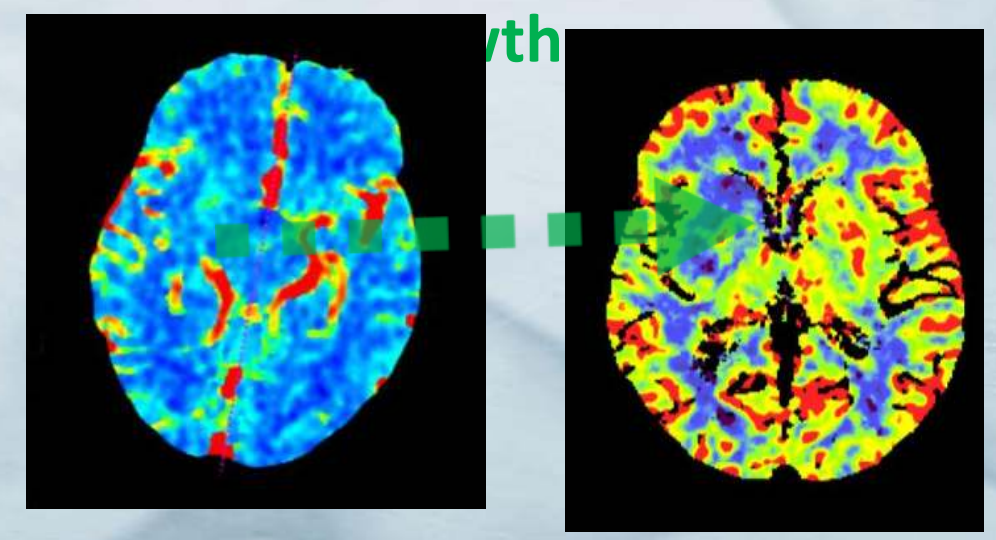

- Better colateral circulation was related with lower infarction growth, Rho=0,33; $p=0,02$.

- Higher CBV-core growth was associated with worse mRS at 3 months (Rho $=0,35 ; p=0,01)$ and larger infarction volume at 24h (Rho=0,44; $=0,002)$. 